\title{
Demographic and Clinical Characteristics of 63 Children with Myelomeningoceles
}

\author{
Youssouf Sogoba1, Seybou Hassane Diallo², Issa Amadou'3, Boubacar Sogoba1, Moussa Diallo1, \\ Benoi Kamaté3, Daouda Mariko1, Coulibaly Oumar4, Quenum Kisito5, Hawa Diall6, \\ Leonie Diakité6, Salimata Diallo², Belco Maiga6, Fousseyni Traoré6, Karamoko Sacko6, \\ Oumar Diallo", Drissa Kanikomo¹, Youssoufa Maiga ${ }^{2}$
}

\author{
${ }^{1}$ Department of Neurosurgery, Hôpital Gabriel Touré, Bamako, Mali \\ ${ }^{2}$ Department of Neurology, Hôpital Gabriel Touré, Bamako, Mali \\ ${ }^{3}$ Department of Pediatric Surgery, Hôpital Gabriel Touré, Bamako, Mali \\ ${ }^{4}$ Department of Neurosurgery, Hôpital du Mali, Bamako, Mali \\ ${ }^{5}$ Department of Neurosurgery, University Hospital of Parakou, Parakou, Benin \\ ${ }^{6}$ Department of Pediatrics, Hôpital Gabriel Touré, Bamako, Mali \\ Email: sogobayoussouf@yahoo.fr
}

How to cite this paper: Sogoba, Y., Diallo, S.H., Amadou, I., Sogoba, B., Diallo, M., Kamaté, B., Mariko, D., Oumar, C., Kisito, Q., Diall, H., Diakité, L., Diallo, S., Maiga, B., Traoré, F., Sacko, K., Diallo, O., Kanikomo, D. and Maiga, Y. (2021) Demographic and Clinical Characteristics of 63 Children with Myelomeningoceles. Open Journal of Modern Neurosurgery, 11, 59-64. https://doi.org/10.4236/ojmn.2021.112007

Received: January 3, 2021

Accepted: March 6, 2021

Published: March 9, 2021

Copyright () 2021 by author(s) and Scientific Research Publishing Inc. This work is licensed under the Creative Commons Attribution International License (CC BY 4.0).

http://creativecommons.org/licenses/by/4.0/

(c) (i) Open Access

\begin{abstract}
Background: Myelomeningocele (MMC) is the most common neural tube defect (NTD) characterized by the extrusion of the spinal cord into a sac filled with cerebrospinal fluid, resulting in lifelong disability. In the general population, the incidence of MMC ranges from 0.3 to 4.5/10,000 births. Live born infants with myelomeningocele have a death rate of approximately $10 \%$. Many factors may play a role in the development of MMC such as environmental and genetic factors. In this study, we present our experience with a group of 63 children afflicted with MMC. Methods: This study was a retrospective analysis of 63 patients with MMC admitted to the neurosurgical department of Gabriel Touré Hospital from September 2017 to August 2018. A detailed history was obtained from the family at presentation. The family history and medical information before and during the pregnancy were compiled. Patients underwent complete physical and neurological examinations. Forty-seven $(74.60 \%)$ patients underwent repair of the MMC and a ventriculoperitoneal shunt was placed in 12 (19\%) patients with accompanying hydrocephalus. The risk factors, neurological status, and surgical results have been analyzed. Results: Of 63 children with MMC admitted to our neurosurgical department, 34 (54\%) were boys and 29 (46\%) were girls. Forty (63.49\%) patients were the children of marriages of second cousins or closer. The mean age of the fathers was 34 years (16 - 65), while that of mothers was 26 years (16 - 38). The pregnancy was unplanned in all cases. Fourteen $(22.22 \%)$ mothers had genitourinary infections, 9 (14.3\%) had malaria and 57 (90.47\%)
\end{abstract}


mothers used analgesics and antibiotics during the pregnancy. Fifty-nine (93.65\%) children were born at term, 58 (92\%) were delivered via normal spontaneous vaginal delivery, and $5(8 \%)$ via cesarean section. Lumbosacral lesions were the most frequent in 27 (42.86\%) patients. Forty-seven (74.60\%) patients underwent repair of the MMC and a ventriculoperitoneal shunt was placed in $12(19 \%)$ patients with accompanying hydrocephalus. Wound infection developed in 2 cases in the postoperative period. The mortality rate was $4.3 \%$. Conclusion: Myelomeningocele is a congenital anomaly for which several risk factors are known as well as environmental and genetic factors. This emphasizes the importance of prevention with folic acid supplementation and genetic advice.

\section{Keywords}

Myelomeningocele, Neural Tube Defects, Hydrocephalus

\section{Introduction}

Myelomeningocele (MMC) is the most common neural tube defect (NTD) [1]. It is characterized by the extrusion of the spinal cord into a sac filled with cerebrospinal fluid, resulting in lifelong disability. In the general population, the incidence of MMC ranges from 0.3 to 4.5/10,000 births [2]. Live born infants with myelomeningocele have a death rate of approximately 10\% [3] [4]. Many factors may play a role in the development of MMC such as environmental and genetic factors [4]. In this study, we present our experience with a group of 63 children afflicted with MMC. The objective was to evaluate the demographic and clinical characteristics for the first time in our department and to compare with data from the literature.

\section{Methods}

This study was a retrospective analysis of 63 patients with MMC admitted to the neurosurgical department of Gabriel Touré Hospital from September 2017 to August 2018. The selection criteria were all the children hospitalized in Gabriel Touré Hospital with myelomeningocele during the study period. A detailed history was obtained from the family at presentation. The family history and medical information before and during the pregnancy was compiled. Patients underwent complete physical and neurological examinations. Ultrasonography and CT scan were the preoperative imaging study in patients with hydrocephaly. Forty-seven (74.60\%) patients underwent repair of the MMC and a ventriculoperitoneal shunt was placed in $12(19 \%)$ patients with accompanying hydrocephalus. The risk factors, neurological status, and surgical results have been analyzed.

\section{Results}

We analyzed 63 children with MMC admitted to our neurosurgical department. 
Thirty-four (54\%) were boys and 29 (46\%) were girls. Forty (63.49\%) patients were the children of marriages of second cousins or closer. The mean age of the fathers was 34 years (16 - 65), while that of mothers was 26 years (16 - 38). Table 1 lists the demographic characteristics of MMC. The pregnancy was unplanned in all cases. Fourteen (22.22\%) mothers had genitourinary infections, 9 (14.3\%) had malaria and 57 (90.47\%) mothers used analgesics and antibiotics during the pregnancy. Fifty-nine (93.65\%) children were born at term, 58 (92\%) were delivered via normal spontaneous vaginal delivery, and $5(8 \%)$ via cesarean section. Lumbosacral lesions were the most frequent in 27 (42.86\%) patients. The clinical characteristics are presented in Table 2. Forty-seven (74.60\%) patients underwent repair of the MMC and a ventriculoperitoneal shunt was placed in 12 (19\%) patients with accompanying hydrocephalus (Figure 1). Fourteen (22.22\%)

Table 1. Demographic characteristics of myelomeningocele.

\begin{tabular}{|c|c|c|}
\hline Demographic characteristics & $\mathrm{n}$ & $\%$ \\
\hline \multicolumn{3}{|l|}{ Maternal age at delivery (years) } \\
\hline $16-25$ & 29 & 46.03 \\
\hline $26-35$ & 30 & 47.60 \\
\hline$>35$ & 4 & 6.35 \\
\hline \multicolumn{3}{|l|}{ Paternal age (years) } \\
\hline $16-25$ & 7 & 11.11 \\
\hline $26-35$ & 25 & 39.68 \\
\hline$>35$ & 31 & 49.20 \\
\hline \multicolumn{3}{|l|}{ Maternal education } \\
\hline Yes & 12 & 19.05 \\
\hline No & 51 & 80.95 \\
\hline \multicolumn{3}{|l|}{ Paternal education } \\
\hline Yes & 20 & 31.75 \\
\hline No & 43 & 68.25 \\
\hline \multicolumn{3}{|l|}{ Consanguineous marriages } \\
\hline Yes & 40 & 63.5 \\
\hline No & 23 & 36.5 \\
\hline \multicolumn{3}{|l|}{ Pregnancy follow-up } \\
\hline Regular & 40 & 63.50 \\
\hline Irregular & 19 & 30.20 \\
\hline none & 4 & 6.30 \\
\hline \multicolumn{3}{|l|}{ Folic acid use } \\
\hline Yes & 59 & 93.65 \\
\hline No & 4 & 6.35 \\
\hline \multicolumn{3}{|l|}{ Smoking } \\
\hline Yes & 0 & 0 \\
\hline No & 63 & 100 \\
\hline
\end{tabular}




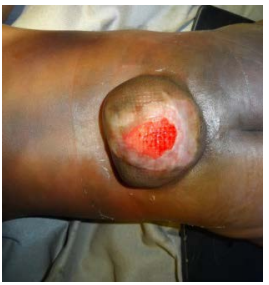

(a)

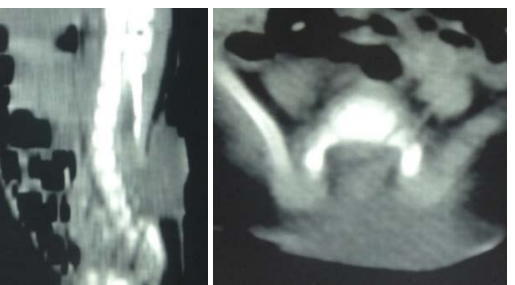

(b)

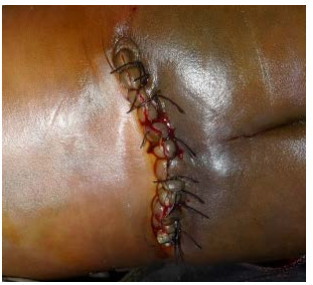

(c)

Figure 1. (a) Clinical photograph of myelomeningocele; (b) CT scan showing the bone defect; (c) Clinical photograph after surgical repair.

Table 2. Clinical characteristics of patients with myelomeningocele.

\begin{tabular}{ccc}
\hline Clinical characteristics & n & $\%$ \\
\hline Site of myelomeningocele & 5 & 7.94 \\
Thoracolumbar & 17 & 26.98 \\
Lumbar & 27 & 42.86 \\
Lumbosacral & 14 & 22.22 \\
Sacral & & \\
Neurological signs & 41 & 65 \\
Paraplegia & 35 & 55.6 \\
Sphincter disturbances & & \\
Orthopedic deformity & 29 & 46 \\
Yes & 34 & 54 \\
No & & \\
Hydrocephalus & & 65.71 \\
Yes & 43 & 31.75 \\
No & 20 & \\
Yes & & 68.25 \\
No & 54 & \\
\hline
\end{tabular}

patients have been lost of view and 2 (3.2\%) died before surgery. In the postoperative period, wound infection developed in 2 cases. In the short term follow-up, 8 (17\%) children showed clinical improvement, 3 (6.38\%) showed neurological deterioration, 15 (32\%) remain unchanged and 21 (44.7\%) had been lost of view. The mortality rate was $4.3 \%$.

\section{Discussion}

MMC is commonly encountered congenital anomaly of the central nervous system (CNS). Most studies have found a female predominance [5] [6]. We found more afflicted boys in our study (54\%). Our ratio is compatible with the survey by some authors [7] [8]. Its occurrence has been associated with a number of factors including extremes of maternal age. The mean age of mothers was 26 
years in our study. Environmental factors may play a role in the higher risk of the pathologic embryo development. In our study, 57 (90.47\%) mothers used analgesics and antibiotics during the pregnancy. The genetic contribution to malformation is described in the literature. Forty (63.5\%) patients with MMC were the children of consanguineous marriages. This emphasizes the importance of prevention in families at higher risk to have a child affected by MMC, what can be achieved by the use of folic acid before and during pregnancy. Maternal folic acid intake is associated with reduced risk of spina bifida [9] [10] [11]. In the present study folic acid was used by mothers irregularly during pregnancy in most of the cases and none before pregnancy because the pregnancy was unplanned in all cases. Although some studies found an increased risk of MMC with smoking [12], no mother in our study was smoking. Low socioeconomic and educational status has been also observed as risk factors for MMC in epidemiologic studies. Fifty-one (80.98\%) mothers and 43 (68.95\%) fathers had no education in this study. The lumbosacral region was found to be most commonly involved in 27 (42.86\%) children, as also reported in the literature. It is well recognized in the literature that there is a significant incidence of hydrocephalus associated with MMC [13]. We found a $68.25 \%$ occurrence of hydrocephalus in our series. Therefore, it is recommended that preoperative brain imaging is performed to assess the evidence of hydrocephalus in any patient who has spinal dysraphism. Orthopedic deformity, paraplegia and sphincter disturbances were preponderant in respectively $29(46 \%), 41(65 \%)$ and $35(55,6 \%)$ children, as also reported in the literature [14] [15].

\section{Conclusion}

Myelomeningocele is a congenital anomaly for which several risk factors are known as well as environmental and genetic factors. This emphasizes the importance of prevention with folic acid supplementation and genetic advice.

\section{Conflicts of Interest}

The authors declare no conflicts of interest regarding the publication of this paper.

\section{References}

[1] Zaganjor, I., Sekkarie, A., Tsang, B.L., Williams, J., Razzaghi, H., Mulinare, J., et al. (2016) Describing the Prevalence of Neural Tube Defects Worldwide: A Systematic Literature Review. PLOS ONE, 11, 1-31. https://doi.org/10.1371/journal.pone.0151586

[2] Larijani, F.J., Moghtaderi, M., Hajizadeh, N. and Assadi, F. (2013) Preventing Kidney Injury in Children with Neurogenic Bladder Dysfunction. International Journal of Preventive Medicine, 12, 1359-1364.

[3] Boulet, S.L., Yang, Q., Mai, C., et al. (2008) Trends in the Postfortification Prevalence of Spina Bifida and Anencephaly in the United States. Birth Defects Research, 82, 527-532. https://doi.org/10.1002/bdra.20468 
[4] Manning, S.M., Jennings, R. and Madsen, J.R. (2000) Pathophysiology, Prevention and Potential Treatment of Neural Tube Defects. Mental Retardation and Developmental Disabilities Research Reviews, 6, 6-14. https://doi.org/10.1002/(SICI)1098-2779(2000)6:1<6::AID-MRDD2>3.0.CO;2-B

[5] Brau, R.H., Rodriquez, R., Ramirez, M.V., Gonzalez, R. and Martinez, V. (1990) Experience in Management of Myelomeningocele in Puerto Rico. Journal of Neurosurgery, 72, 726-731. https://doi.org/10.3171/jns.1990.72.5.0726

[6] Steinbok, P., Irvine, B. and Cochrane, D.D. (1992) Long-Term Outcome and Complication of Children Born with Myelomeningocele. Child's Nervous System, 8, 92-96. https://doi.org/10.1007/BF00298448

[7] Greene, W.B., Terry, R.C., DeMasi, R.A. and Herrington, R.T. (1991) Effect of Race and Gender on Neurological Level in Myelomeningocele. Developmental Medicine \& Child Neurology, 33, 110-117. https://doi.org/10.1111/j.1469-8749.1991.tb05089.x

[8] Ketabchi, S.E., Ghodsi, S.M. and Nejat, F. (2001) Incidence of Anomalies in Newborns at Two Obstetric Centers in Tehran. Journal of Medical Council of Iran, 18, 277-281.

[9] Czeizel, A.E. and Dudas, I. (1992) Prevention of the First Occurrence of Neural-Tube Defects by Periconceptional Vitamin Supplementation. The New England Journal of Medicine, 327, 1832-1835.

[10] Czeizel, A.E. (1993) Prevention of Congenital Abnormalities by Periconceptional Multivitamin Supplementation. BMJ, 306, 1645-1648.

https://doi.org/10.1136/bmj.306.6893.1645

[11] Kadir, R.Z., Sabin, C., Whitlow, B., Brockbank, E. and Economides, D. (1999) Neural Tube Defects and Periconceptional Folic Acid in England and Wales: Retrospective Study. BMJ, 319, 92-93. https://doi.org/10.1136/bmj.319.7202.92

[12] Jensen, L.E., Hoess, K., Whitehead, A.S. and Mitchell, L.E. (2005) The NAT1 C1095A Polymorphism, Maternal Multivitamin Use and Smoking, and the Risk of Spina Bifida. Birth Defects Research: Part A, Clinical and Molecular Teratology, 73, 512-516. https://doi.org/10.1002/bdra.20143

[13] Bier, J.B., Morales, Y., Liebling, J., Geddes, L. and Kim, E. (1997) Medical and Social Factors Associated with Cognitive Outcome in Individuals with Myelomeningocele. Developmental Medicine \& Child Neurology, 39, 263-266. https://doi.org/10.1111/j.1469-8749.1997.tb07423.x

[14] Northrup, H. and Volcik, K.A. (2000) Spina Bifida and Other Neural Tube Defects. Current Problems in Pediatric and Adolescent Health Care, 30, 315-337.

[15] Skari, H., Bjornland, K., Bjornstad-Ostensen, A., Haugen, G. and Emblem R. (1998) Consequences of Prenatal Diagnosis: A Preliminary Report on Neonates with Congenital Malformations. Acta Obstetricia et Gynecologica Scandinavica, 77, 635-642. https://doi.org/10.1034/j.1600-0412.1998.770610.x 